\title{
Gram-Negative Bacteria Harboring Multiple Carbapenemase Genes, United States, 2012-2019
}

D. Cal Ham, Garrett Mahon, Sandeep K. Bhaurla, Sam Horwich-Scholefield, Liore Klein, Nychie Dotson, J. Kamile Rasheed, Gillian McAllister, Richard A. Stanton, Maria Karlsson, David Lonsway, Jennifer Y. Huang, Allison C. Brown, Maroya Spalding Walters

Reports of organisms harboring multiple carbapenemase genes have increased since 2010. During October 2012April 2019, the Centers for Disease Control and Prevention documented 151 of these isolates from 100 patients in the United States. Possible risk factors included recent history of international travel, international inpatient healthcare, and solid organ or bone marrow transplantation.

Cart arbapenems have been standard treatments for multidrug-resistant gram-negative bacilli infections since 1985, when they were approved for clinical use in the United States (https: / / www.accessdata.fda. gov/drugsatfda_docs/label/2016/050587s0741bl. pdf). Carbapenem-resistant organisms (CROs) are a growing public health concern as carbapenemaseproducing CROs become more common (1). Several recent reports describe CROs carrying multiple carbapenemase genes (multi-CPOs) (2-8). We describe multi-CPOs reported to the Centers for Disease Control and Prevention (CDC; Atlanta, GA, USA) during 2012-2019.

\section{The Study}

CDC receives reports of carbapenemase-producing CROs from health departments, public health laboratories, healthcare facilities, and isolates sent to CDC for confirmatory testing. In 2016, CDC established

Author affiliations: Centers for Disease Control and Prevention, Atlanta, Georgia, USA (D.C. Ham, G. Mahon, J.K. Rasheed, G. McAllister, R.A. Stanton, M. Karlsson, D. Lonsway, J.Y. Huang, A.C. Brown, M.S. Walters); Los Angeles County Department of Public Health, Los Angeles, California, USA (S.K. Bhaurla); California Department of Public Health, Richmond, California, USA (S. Horwich-Scholefield); Maryland Department of Health, Baltimore, Maryland, USA (L. Klein); Florida Department of Health, Tallahassee, Florida, USA (N. Dotson)

DOI: https://doi.org/10.3201/eid2709.210456 the Antibiotic Resistance Laboratory Network (AR Lab Network), a national network of 55 public health laboratories that test carbapenem-resistant Enterobacterales (CRE), carbapenem-resistant Pseudomonas aeruginosa (CRPA), and carbapenem-resistant Acinetobacter baumannii (CRAB) isolates for carbapenemase genes.

We reviewed CDC and AR Lab Network reports of multi-CPOs identified during January 1, 2010-April 30, 2019. We defined a multi-CPO case as Enterobacterales, Pseudomonas spp., or A. baumannii isolated from any specimen source and carrying genes encoding $>1$ carbapenemase routinely tested for at CDC and the AR Lab Network (CRE, CRPA, and CRAB isolates were tested for Klebsiella pneumoniae carbapenemase [KPC], New Delhi metallo- $\beta$-lactamase [NDM], Verona integron-encoded metallo- $\beta$-lactamase [VIM], active-on-imipenem metallo- $\beta$-lactamase [IMP], and oxacillinase [OXA]-48-like $\beta$-lactamases; CRAB isolates also were tested for OXA-23, OXA-24/40, and OXA58-like $\beta$-lactamases). Whole-genome sequencing (WGS) was conducted on a subset of isolates (Appendix, https://wwwnc.cdc.gov/EID/article/27/9/210456-App1.pdf). We defined an incident case as the first isolation of a unique organism-carbapenemase combination in each patient.

As part of routine public health investigations, health departments reviewed medical records and laboratory reports for patient demographic data and risk factors for exposure. We conducted descriptive analyses using SAS version 9.4 (https://www.sas. com) and calculated Pearson $\chi^{2}$ score using SPSS Statistics 21.0 (IBM, https:/ / www.ibm.com).

During January 2010-April 2019, a total of 151 multi-CPO isolates, including those from 105 incident cases, were identified in 100 unique patients; the first case was identified in October 2012 (Table 1; Appendix Tables 1,2). Among 89 (84.8\%) incident cases 
Table 1. Incident cases of gram-negative bacilli harboring multiple carbapenemase genes, United States, January 2012-April 2019*

\begin{tabular}{|c|c|c|c|c|c|c|c|c|c|}
\hline \multirow[b]{2}{*}{ Organism } & \multicolumn{8}{|c|}{ Carbapenemase combinations } & \multirow[b]{2}{*}{$\begin{array}{c}\text { Total, } N= \\
105\end{array}$} \\
\hline & $\begin{array}{c}\text { NDM + OXA- } \\
48-\text { like }\end{array}$ & $\begin{array}{c}\mathrm{KPC}+ \\
\mathrm{NDM}\end{array}$ & $\begin{array}{c}\text { KPC + } \\
\text { VIM }\end{array}$ & $\begin{array}{c}\text { NDM + } \\
\text { VIM }\end{array}$ & $\begin{array}{c}\text { KPC + OXA- } \\
48-\text { like }\end{array}$ & $\begin{array}{l}\text { NDM }+ \\
\text { IMP }\end{array}$ & $\begin{array}{l}\text { NDM + } \\
\text { OXA-23 }\end{array}$ & $\begin{array}{c}\text { NDM + } \\
\text { OXA-48- } \\
\text { like + VIM }\end{array}$ & \\
\hline Enterobacterales & 64 & 23 & 6 & 0 & 2 & 0 & 0 & 1 & 96 \\
\hline Citrobacter freundii & 0 & 0 & 1 & 0 & 1 & 0 & 0 & 0 & 2 \\
\hline Enterobacter cloacae & 0 & 8 & 1 & 0 & 0 & 0 & 0 & 0 & 9 \\
\hline Escherichia coli & 17 & 3 & 0 & 0 & 0 & 0 & 0 & 0 & 20 \\
\hline Klebsiella aerogenes & 0 & 0 & 1 & 0 & 0 & 0 & 0 & 0 & 1 \\
\hline K. oxytoca & 0 & 0 & 1 & 0 & 0 & 0 & 0 & 0 & 1 \\
\hline K. pneumoniae & 46 & 12 & 2 & 0 & 1 & 0 & 0 & 1 & 62 \\
\hline Providencia rettgeri & 1 & 0 & 0 & 0 & 0 & 0 & 0 & 0 & 1 \\
\hline Pseudomonadales & 0 & 0 & 1 & 4 & 0 & 2 & 2 & 0 & 9 \\
\hline Pseudomonas aeruginosa & 0 & 0 & 1 & 3 & 0 & 2 & 0 & 0 & 6 \\
\hline Pseudomonas fluorescens & 0 & 0 & 0 & 1 & 0 & 0 & 0 & 0 & 1 \\
\hline Acinetobacter baumannii & 0 & 0 & 0 & 0 & 0 & 0 & 2 & 0 & 2 \\
\hline
\end{tabular}

*IMP, active-on-imipenem metallo- $\beta$-lactamase; KPC, Klebsiella pneumoniae carbapenemase; NDM, New Delhi metallo- $\beta$-lactamase; OXA, oxacillinase; VIM, Verona integron-encoded metallo- $\beta$-lactamase.

reported since AR Lab Network testing began in 2017, a total of 15 were reported in 2017, 51 in 2018, and 23 in the first 4 months of 2019. Among the isolates tested through the AR Lab Network during 2017-2019, a total of 111/28,390 (0.391\%) CRE, 5/19,609 (0.025\%) CRPA, and 2/2,443 (0.082\%) CRAB isolates harbored multiple carbapenemase genes; we included CRAB isolates tested only during January 2018-April 2019. Incident cases were reported in 29 US states and the District of Columbia. Enterobacterales accounted for $96(91.4 \%)$ of the incident multi-CPO cases; in addition, 7 (6.7\%) were Pseudomonas spp. and 2 (1.9\%) were A. baumannii. Among 96 incident Enterobacterales cases, the most common $(46 ; 47.9 \%)$ organismgene combination was K. pneumoniae harboring $b l a_{\mathrm{NDM}}$ and $b l a_{\text {OXA-48-like }}$.

WGS was conducted on 46 isolates from incident cases, identifying 6 sequence types of Enterobacter cloacae, 9 of Escherichia coli, and 11 of K. pneumoniae. WGS identified 21 isolates harboring $b l a_{\mathrm{NDM}-1}, 16$ harboring $b l a_{\mathrm{NDM}-5^{\prime}} 16$ harboring $b l a_{\mathrm{OXA}-181^{\prime}}$ and 11 harboring bla $_{\mathrm{KPC}-3}$ (Appendix Table 2). In total, 8 incident cases were associated with 2 separate clusters at acute care hospitals.

The median age of patients at the time of multiCPO identification was 63 years (range 2-94 years). Among 93 incident cases with available data, 62 $(66.7 \%)$ occurred in patients who had traveled internationally in the 12 months before their incident culture. Among patients with a history of international travel, most $(89.5 \%)$ had received inpatient healthcare while abroad. Association with international travel varied by carbapenemase combination; among 59 incident cases with available data that harbored $b l a_{\mathrm{NDM}}$ and $b l a_{\text {OXA-48-like' }} 47$ (79.7\%) occurred in patients who reported international travel; only 5/19 (26.3\%; $\mathrm{p}<0.01)$ incident cases that harbored $b l a_{\mathrm{KPC}}$ and $b l a_{\mathrm{NDM}}$ occurred in patients who reported international travel. Among the 80 incident cases with available data, $14(17.5 \%)$ occurred in patients with a history of solid organ or bone marrow transplantation before their incident culture (Table 2).

Multi-CPOs in this convenience sample were identified in many states and included diverse organisms, sequence types, and carbapenemase gene combinations and variants, suggesting that clonal spread is not responsible for their emergence. Variants harboring $b l a_{\mathrm{KPC}-4}$ and $b l a_{\mathrm{NDM}-4^{\prime}}$ which are uncommon in the United States, were identified (9-11). Most incident cases of CROs harboring multiple carbapenemase genes occurred in patients who had a recent history of international travel and inpatient healthcare outside the United States; we also identified history of solid organ or bone marrow transplant as a potential risk factor.

Receiving healthcare abroad and, more recently, international travel without medical care are risk factors for acquiring carbapenemase-producing organisms among patients in the United States (9). However, in this study, one third of cases occurred in persons without known recent travel outside the United States. For some carbapenemase combinations, such as isolates harboring $b l a_{\mathrm{KPC}}$ and $b l a_{\mathrm{NDM}}$, most cases occurred in patients who had not recently traveled internationally. In addition, identifying facility clusters raises further concerns about dissemination of these multidrug-resistant organisms among healthcare facilities in the United States.

The emergence of multi-CPOs has clinical, laboratory testing, and public health implications. The ceftazidime/avibactam, meropenem/vaborbactam, and imipenem/cilastatin/relebactam combination therapies have increased treatment options for CREs that produce KPC and OXA-48-like carbapenemases; growth in the proportion of isolates that co-harbor 
Table 2. Characteristics and exposures of incident cases of gram-negative bacilli harboring multiple carbapenemase genes, United States, January 2012-April 2019*

\begin{tabular}{|c|c|c|c|c|c|c|c|}
\hline \multirow[b]{2}{*}{$\begin{array}{l}\text { Characteristics and } \\
\text { exposures }\end{array}$} & \multicolumn{4}{|c|}{ Enterobacterales $†$} & \multirow{2}{*}{$\begin{array}{c}\text { Pseudomonas } \\
\text { spp., } ¥ \text { KPC + } \\
\text { VIM, NDM + } \\
\text { VIM, or } \\
\text { NDM + IMP }\end{array}$} & \multirow{2}{*}{$\begin{array}{c}\text { Acinetobacter } \\
\text { baumannii, } \\
\text { NDM + } \\
\text { OXA-23 } \\
\end{array}$} & \multirow[b]{2}{*}{ Total } \\
\hline & $\begin{array}{l}\mathrm{NDM}+ \\
\mathrm{OXA}-48 \S\end{array}$ & $\mathrm{KPC}+\mathrm{NDM}$ & $\begin{array}{c}\mathrm{KPC}+ \\
\mathrm{VIM}\end{array}$ & $\begin{array}{l}\mathrm{KPC}+ \\
\mathrm{OXA}-48 \\
\end{array}$ & & & \\
\hline Total no. $(\%)$ cases & $65(100.0)$ & $23(100.0)$ & $6(100.0)$ & $2(100.0)$ & $7(100.0)$ & $2(100.0)$ & $105(100.0)$ \\
\hline \multicolumn{8}{|c|}{ Region of specimen collection } \\
\hline South & $22 / 65(33.8)$ & 9/23 (39.1) & 2/6 (33.3) & 0 & 3/7 (42.9) & $1 / 2(50.0)$ & $37 / 105(35.2)$ \\
\hline West & 22/65 (33.8) & $3 / 23(13.0)$ & 2/6 (33.3) & 0 & $1 / 7(14.3)$ & & (26.7) \\
\hline Northeast & $14 / 65(21.5)$ & $5 / 23(21.7)$ & 0 & 0 & $2 / 7(28.6)$ & & $5(20.0)$ \\
\hline Midwest & $7 / 65(10.8)$ & $6 / 23(26.1)$ & $2 / 6(33.3)$ & $2 / 2(100.0)$ & $1 / 7(14.3)$ & $1 / 2(50.0)$ & $5(18.1)$ \\
\hline \multicolumn{8}{|c|}{ Location of specimen collection } \\
\hline Acute care hospital & $51 / 57(89.5)$ & $18 / 22(81.8)$ & $3 / 4(75.0)$ & $2 / 2(100.0)$ & $5 / 7(71.4)$ & 0 & $79 / 94(84.0)$ \\
\hline Outpatient facility & $5 / 57(8.8)$ & $1 / 22(4.5)$ & 0 & 0 & $2 / 7(28.6)$ & $1 / 2(50.0)$ & $9 / 94(9.6)$ \\
\hline $\begin{array}{l}\text { Long-term acute care } \\
\text { hospital }\end{array}$ & 0 & $1 / 22(4.5)$ & $1 / 4(25.0)$ & 0 & 0 & $1 / 2(50.0)$ & $3 / 94(3.2)$ \\
\hline Skilled nursing facility & 0 & $2 / 22(9.1)$ & 0 & 0 & 0 & 0 & $2 / 94(2.1)$ \\
\hline $\begin{array}{l}\text { Joint acute care } \\
\text { hospital/ inpatient } \\
\text { rehabilitation facility }\end{array}$ & $1 / 57(1.8)$ & 0 & 0 & 0 & 0 & 0 & $.1)$ \\
\hline $\begin{array}{l}\text { Hospitalization in previous } \\
12 \text { mo, United States\# }\end{array}$ & $44 / 56(78.6)$ & $19 / 23(82.6)$ & $4 / 5(80.0)$ & $2 / 2(100.0)$ & $4 / 7(57.1)$ & $2 / 2(100.0)$ & $75 / 95(78.9)$ \\
\hline \multicolumn{8}{|c|}{ International travel in previous $12 \mathrm{mo}^{\star *}$} \\
\hline Yes & 47/59 (79.7)†† & 5/19 (26.3)†† & $1 / 4(25.0)$ & $1 / 2(50.0)$ & $7 / 7(100.0)$ & $1 / 2(50.0)$ & $62 / 93(66.7)$ \\
\hline $\begin{array}{l}\text { International inpatient } \\
\text { healthcare } \ddagger \ddagger\end{array}$ & $40 / 43(93.0)$ & $3 / 4(75.0)$ & $0 / 1$ & $0 /$ & $6 / 7(85.7)$ & $1 / 1(100.0)$ & 39.5) \\
\hline India & 29/39 (74.4) & 1/3 (33.3) & & $1 / 1(100.0)$ & $3 / 6(50.0)$ & $1 / 1(100.0)$ & $35 / 50$ \\
\hline Other§§ & 2.8) & $2 / 3(66.7)$ & & 0 & $2 / 6(33.3)$ & $0 / 1$ & 18.0) \\
\hline Pakistan & $.7)$ & $0 / 3$ & & $0 / 1$ & $0 / 6$ & 1/1 (100.0) & (8.0) \\
\hline Egypt & 1) & $0 / 3$ & & $0 / 1$ & $0 / 6$ & $0 / 1$ & $2 / 50(4.0)$ \\
\hline Vietnam & $1 / 39$ & $0 / 3$ & & $0 / 1$ & $1 / 6(16.7)$ & $0 / 1$ & $2 / 50(4.0)$ \\
\hline No & $12 / 59$ & 14/19 (73.7) & $3 / 4(75.0)$ & $1 / 2(50.0)$ & $0 / 7$ & $1 / 2(50.0)$ & $3.3)$ \\
\hline US hospitalization & $11 / 12$ & $12 / 14(85.7)$ & $3 / 3(100.0)$ & $1 / 1(100.0)$ & & $1 / 1(100.0)$ & $0.3)$ \\
\hline Transplant recipientףाT & $11 / 48(22.9)$ & $4 / 17(23.5)$ & $0 / 5$ & $1 / 2(50.0)$ & $1 / 6(16.7)$ & $0 / 2$ & $17 / 80$ \\
\hline $\begin{array}{l}\text { Before incident case } \\
\text { Transplant to incident } \\
\text { case, d, median (IQR) }\end{array}$ & $8 / 11(72.7)$ & 4/4 (100.0) & & $1 / 1(100)$ & $1 / 1(100.0)$ & & $\begin{array}{l}14 / 17(82.4) \\
44(15-446)\end{array}$ \\
\hline $\begin{array}{l}\text { After incident case } \\
\text { Incident case to } \\
\text { transplant, d, median } \\
\text { (IQR) }\end{array}$ & 3/11 (27.3) & $0 / 4$ & & $0 / 1$ & $0 / 1$ & & $\begin{array}{c}3 / 17(17.6) \\
96(28-188)\end{array}$ \\
\hline \multicolumn{8}{|l|}{ Type of transplant\#\# } \\
\hline Solid organ & $11 / 11(100.0)$ & $2 / 4(50.0)$ & & $0 / 1$ & $0 / 1$ & & $13 / 17$ \\
\hline Kidney & $7 / 11(63.6)$ & $0 / 2$ & & & & & $7 / 13(53.8)$ \\
\hline Liver & $3 / 11(27.3)$ & $1 / 2(50.0)$ & & & & & 4/13 (30.8) \\
\hline Lung & $1 / 11(9.1)$ & $1 / 2(50.0)$ & & & & & 2/13 (15.4) \\
\hline Bone marrow & $0 / 11$ & $2 / 4(50.0)$ & & $1 / 1(100.0)$ & $1 / 1(100.0)$ & & $4 / 17(23.5)$ \\
\hline \multicolumn{8}{|c|}{ 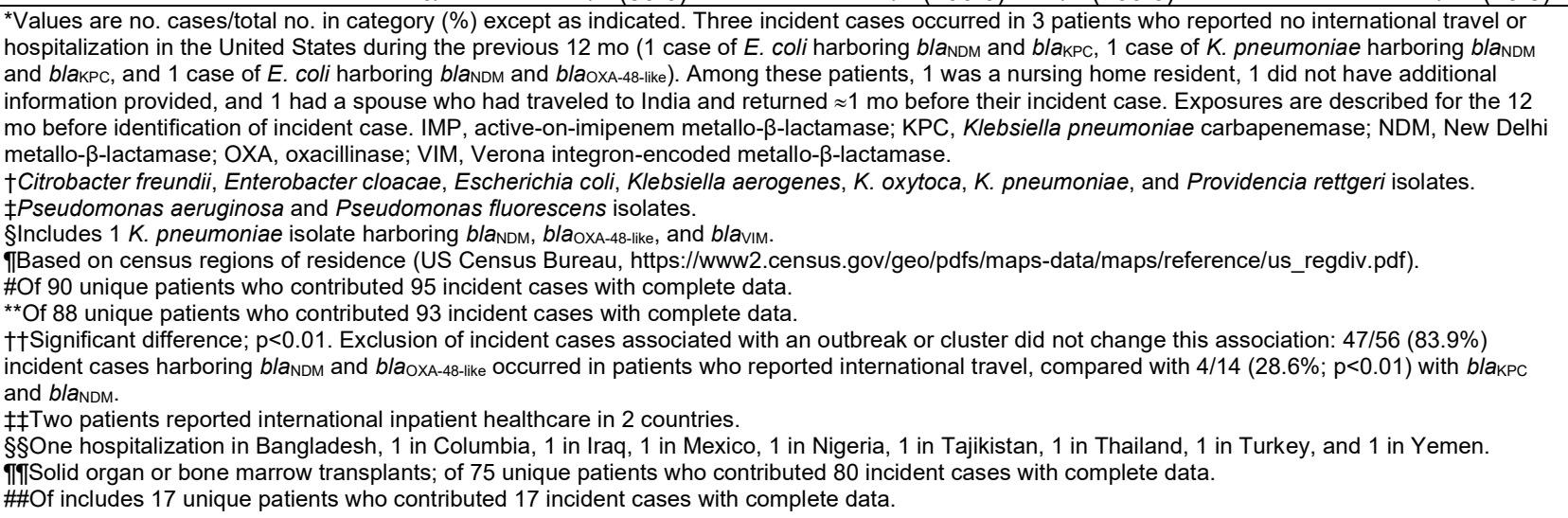 } \\
\hline
\end{tabular}


$b l a_{\mathrm{NDM}}$ jeopardizes the usefulness of these therapies. We noted $1 P$. aeruginosa isolate harboring $b l a_{\mathrm{NDM}-1}$ and $b l a_{\mathrm{IMP}-1}$; this isolate was panresistant to all antimicrobial drugs tested (12). A high proportion (17.5\%) of cases occurred among patients with history of solid organ or bone marrow transplantation before their index culture, a population for whom CRO infections are associated with worse outcomes than patients without transplants $(13,14)$. In comparison, only $3.1 \%$ of patients with CRE reported to the Multi-Site Gram-Negative Surveillance Initiative at CDC during 2012-2019 had a history of transplant before their positive culture (15; I. See, CDC, pers. comm., 2021 Jan 19); whether multiCPOs are emerging in this population requires careful monitoring. Finally, hierarchical testing algorithms, in which testing is halted after detection of an initial carbapenemase, might not identify additional, less common carbapenemases (e.g., hierarchical testing might not identify $b l a_{\mathrm{VIM}}$ in an isolate with $b l a_{\mathrm{KPC}}$ and $\left.b l a_{\mathrm{VIM}}\right)$.

The first limitation of our analysis is that these data represent a passively reported convenience sample during a period in which multiple changes in testing practices, including the establishment of the AR Lab Network, occurred. For this reason, we cannot determine whether multi-CPOs became more common during the evaluation period. Second, CROs from patients with a history of healthcare abroad might have been selected for mechanism testing, biasing detection toward this risk factor; bias might have been more influential early in the investigation period, when testing resources were limited. Finally, this analysis did not systematically document outpatient healthcare exposures and residence in long-term care facilities, which also might be relevant sources of exposure; 1 case in this analysis was associated with invasive urologic procedures abroad (7).

\section{Conclusions}

Multi-CPOs in healthcare facilities are an emerging concern in the United States. Although hospitalization outside the United States was the most common risk factor, we found a substantial proportion of cases that were probably acquired in healthcare facilities in the United States. Several measures might slow further spread. First, screening patients who were recently hospitalized outside the United States can help prevent additional introductions of carbapenemase genes not commonly found in the United States. Second, molecular testing to identify carbapenemase genes should not use hierarchical algorithms. Finally, when a multiCPO is identified, public health officials should assess for potential transmission (https://www.cdc.gov/ hai/containment/guidelines.html).

\section{Acknowledgments}

We thank our state and local health department partners for providing information from their public health response work, including Eleanor Adams, Melissa Anacker, Michael Anderson, Sandi Arnold, Rachana Bhattarai, Emily Blake, Justin Blanding, Janine Bodnar, Erin Breaker, the California Department of Public Health - Microbial Diseases Laboratory, Theresa Canulla, Rebekah Carman, Savannah Carrico, Melanie Chervony, Kaitlyn Chorbi, Kailee Cummings, Jennifer Dale, Thi Dang, Marisa D'Angeli, Jonathan Daniels, Catherine Dominguez, Andrea Flinchum, Bobbiejean Garcia, Michael Gosciminski, Shermalyn Greene, Annastasia Gross, Alison Laufer Halpin, Ishrat KamalAhmed, Marion Kainer, Kelly Kauber, Alyssa Kent, Elizabeth Kim, Cara Bicking Kinsey, Sarah Kogut, Pat Kopp, Adrian Lawsin, James Lewis, Ruth Lynfield, Jennifer MacFarquhar, Patricia McAuley, Susannah McKay, Sara McNamara, the Maryland Public Health Laboratory Antibiotic Resistance Lab Network Working Group, Derek Miller, Shannon Morris, Jeanne Negley, Julie Paoline, Brittany Pattee, Sean O'Malley, Naveen Patil, Elizabeth Nazarian, Caitlin Pedati, Amy Recker, Jacqueline Reuben, Emily Schneider, Amanda Smith, Elizabeth Soda, Kevin Spicer, Emily Snavely, Bryna Stacey, Maureen Tierney, Angela Tang, Michael Tran, Paula Snippes Vagnone, Christine Wagner, JoAnna Wagner, and Phillip Weeber.

S.H.-S. received a Merck Investigational Studies Program Grant (November 2019-November 2020) for work on carbapenem-resistant Enterobacteriaceae surveillance at the California Department of Public Health (Los Angeles, California, USA). M.K. has a US patent application (application no. 16/615,725) filed November 21, 2019 for detection of $b l a_{\mathrm{IMP}}$ antimicrobial resistance genes.

\section{About the Author}

Dr. Ham is a public health physician at the National Center for Emerging and Zoonotic Infectious Diseases, Centers for Disease Control and Prevention, Atlanta, Georgia, USA. His primary research focus is antimicrobial resistance among gram-negative and gram-positive bacteria.

\section{References}

1. Centers for Disease Control and Prevention. Biggest threats and data: 2019 AR threats report. 2019 [cited 2020 Oct 7]. https://www.cdc.gov/drugresistance/ biggest-threats.html

2. Doi Y, O'Hara JA, Lando JF, Querry AM, Townsend BM, Pasculle AW, et al. Co-production of NDM-1 and OXA-232 by Klebsiella pneumoniae. Emerg Infect Dis. 2014;20:163-5. https://doi.org/10.3201/eid2001.130904 
3. Jhang J, Wang HY, Yoo G, Hwang GY, Uh Y, Yoon KJ. NDM-5 and OXA-48 co-producing uropathogenic Escherichia coli isolate: first case in Korea. Ann Lab Med. 2018;38:277-9. https://doi.org/10.3343/alm.2018.38.3.277

4. Lyman M, Walters M, Lonsway D, Rasheed K, Limbago B, Kallen A. Notes from the field: carbapenem-resistant Enterobacteriaceae producing OXA-48-like carbapenemases United States, 2010-2015. MMWR Morb Mortal Wkly Rep. 2015;64:1315-6. https:// doi.org/10.15585/ mmwr.mm6447a3

5. Meletis G, Chatzidimitriou D, Malisiovas N. Double- and multi-carbapenemase-producers: the excessively armored bacilli of the current decade. Eur J Clin Microbiol Infect Dis. 2015;34:1487-93. https:/ / doi.org/10.1007/s10096-015-2379-9

6. Politi L, Gartzonika K, Spanakis N, Zarkotou O, Poulou A, Skoura L, et al. Emergence of NDM-1-producing Klebsiella pneumoniae in Greece: evidence of a widespread clonal outbreak. J Antimicrob Chemother. 2019;74:2197-202. https://doi.org/10.1093/jac/dkz176

7. Vannice K, Benoliel E, Kauber K, Brostrom-Smith C, Montgomery P, Kay M, et al. Notes from the field: clinical Klebsiella pneumoniae isolate with three carbapenem resistance genes associated with urology procedures - King County, Washington, 2018. MMWR Morb Mortal Wkly Rep 2019;68:667-8. https://doi.org/10.15585/mmwr.mm6830a4

8. Yasmin M, Fouts DE, Jacobs MR, Haydar H, Marshall SH, White R, et al. Monitoring ceftazidime-avibactam and aztreonam concentrations in the treatment of a bloodstream infection caused by a multidrug-resistant Enterobacter sp. carrying both Klebsiella pneumoniae carbapenemase- 4 and New Delhi metallo- $\beta$-lactamase-1. Clin Infect Dis. 2020;71:1095-8. https://doi.org/10.1093/cid/ciz1155

9. van Duin D, Doi Y. The global epidemiology of carbapenemase-producing Enterobacteriaceae. Virulence. 2017; 8:460-9. https://doi.org/10.1080/21505594.2016.1222343

10. Khan AU, Maryam L, Zarrilli R. Structure, genetics and worldwide spread of New Delhi metallo- $\beta$-lactamase (NDM): a threat to public health. BMC Microbiol. 2017;17:101. https:/ / doi.org/10.1186/s12866-017-1012-8

11. Stoesser N, Sheppard AE, Peirano G, Anson LW,

Pankhurst L, Sebra R, et al. Genomic epidemiology of global Klebsiella pneumoniae carbapenemase (KPC)-producing Escherichia coli. Sci Rep. 2017;7:5917. https://doi.org/ 10.1038/s41598-017-06256-2

12. Lonsway DR, Bhatnagar A, Balbuena R, Stanton R, McAllister G, Halpin AL, et al. Characterization of a pan-resistant Pseudomonas aeruginosa containing bla $_{N D M-1}$ and $b_{l a} a_{I M P-1}$. ASM Microbe 2019; 2019 Jun 22; San Francisco, CA, USA.

13. Pouch SM, Satlin MJ. Carbapenem-resistant Enterobacteriaceae in special populations: solid organ transplant recipients, stem cell transplant recipients, and patients with hematologic malignancies. Virulence. 2017;8:391-402. https://doi.org/ 10.1080/21505594.2016.1213472

14. Smibert O, Satlin MJ, Nellore A, Peleg AY. Carbapenemresistant Enterobacteriaceae in solid organ transplantation: management principles. Curr Infect Dis Rep. 2019;21:26. https:/ / doi.org/10.1007/s11908-019-0679-4

15. Centers for Disease Control and Prevention. Multi-site gram-negative surveillance initiative. 2021 [cited 2021 Jan 19]. https://www.cdc.gov/hai/eip/mugsi.html

Address for correspondence: D. Cal Ham, Centers for Disease Control and Prevention, 1600 Clifton Rd NE, Mailstop A-31, Atlanta, GA 30329-4027, USA; email: ink4@cdc.gov

\section{EID podcast
A Decade of Fatal
Human Eastern Equine Encephalitis Virus Infection, Alabama}

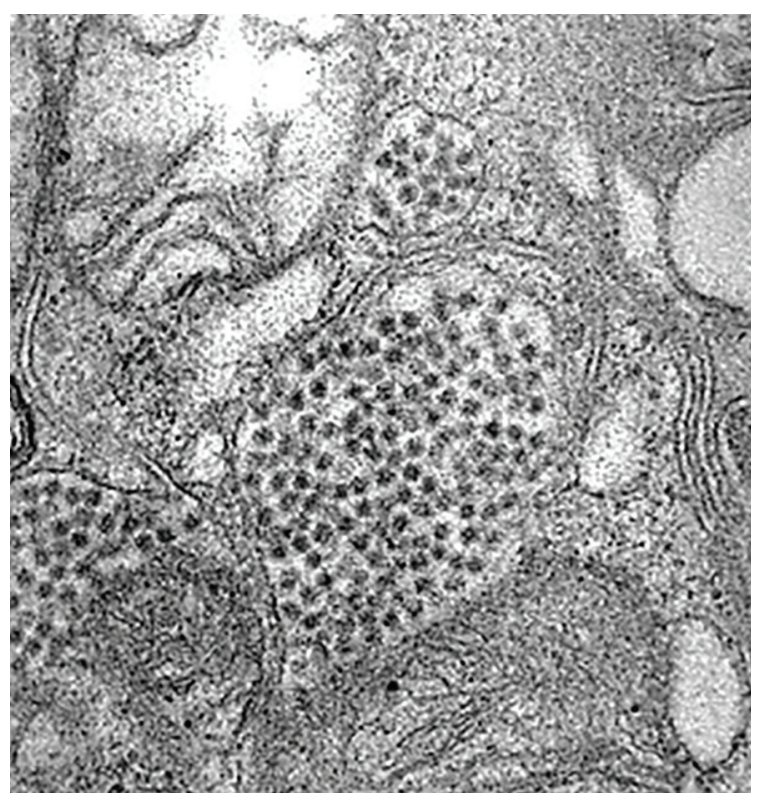

After infection with eastern equine encephalitis virus, the immune system races to clear the pathogen from the body. Because the immune response occurs so quickly, it is difficult to detect viral RNA in serum or cerebrospinal samples.

In immunocompromised patients, the immune response can be decreased or delayed, enabling the virus to continue replicating. This delay gave researchers the rare opportunity to study the genetic sequence of isolated viruses, with some surprising results.

In this EID podcast, Dr. Holly Hughes, a research microbiologist at CDC in Fort Collins, Colorado, describes a fatal case of mosquitoborne disease.

\section{Visit our website to listen: https: / /go.usa.gov/xFUhU}

EMERGING INFECTIOUS DISEASES 